\title{
Erratum to: Characterization and analysis of structural isomers of dimethyl methoxypyrazines in cork stoppers and ladybugs (Harmonia axyridis and Coccinella septempunctata)
}

Petra Slabizki • Charlotte Legrum •

Reinhard Meusinger • Hans-Georg Schmarr

Received: 3 September 2014 / Accepted: 3 September 2014/Published online: 17 September 2014

(C) Springer-Verlag Berlin Heidelberg 2014

Erratum to: Anal Bioanal Chem

DOI 10.1007/s00216-014-8049-4

Unfortunately a wrong file was uploaded and reproduced as

Fig. 7. The correct Fig. 7 is printed below:

The online version of the original article can be found at http:// dx.doi.org/10.1007/s00216-014-8049-4.

P. Slabizki • C. Legrum • H.-G. Schmarr $(\bowtie)$

Dienstleistungszentrum Ländlicher Raum (DLR) Rheinpfalz,

Competence Center for Wine Research, Breitenweg 71,

67435 Neustadt an der Weinstraße, Germany

e-mail: hans-georg.schmarr@dlr.rlp.de

C. Legrum

Faculty of Food Chemistry and Toxicology, Technical University of Kaiserslautern, Erwin-Schrödinger-Straße 52, 67663 Kaiserslautern,

Germany

R. Meusinger

Institute of Organic Chemistry and Biochemistry, University of Technology Darmstadt, Alarich-Weiss-Str. 4, 64287 Darmstadt,

Germany 


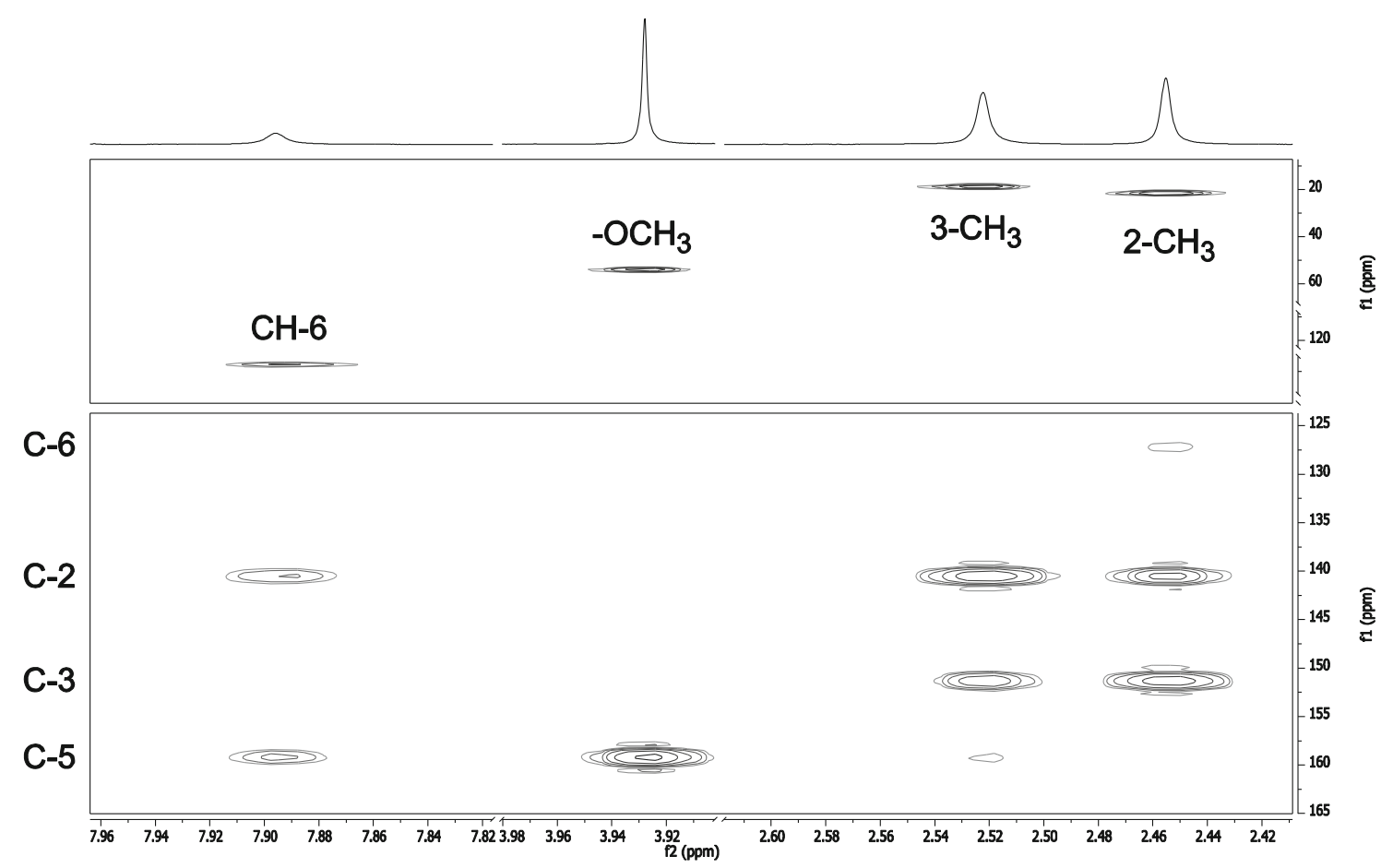

